\title{
Wer hat Angst vor der grauen Welle?
}

\section{Anna Sax}

Lic. oec. publ., MHA, Mitglied der Redaktion

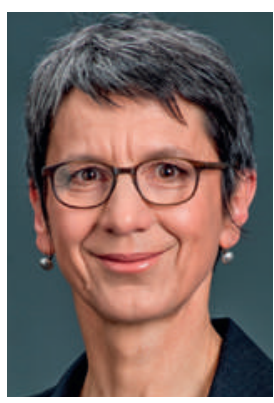

1 Bestandesaufnahme und Perspektiven im Bereich der Langzeitpflege. Bericht des Bundesrats vom 25. Mai 2016.

2 www.grossmuetter.ch

anna.sax[at]saez.ch
Ich gehöre der Generation an, die in etwa 20-30 Jahren als «graue Welle» über unser Land fluten wird. Wir werden zu Hunderttausenden dement umherirren, mit gebrochenen Knochen die Notfallabteilungen belagern, uns in die Hosen machen und den öffentlichen Verkehr verlangsamen, weil wir nicht schnell genug ein- und aussteigen können. Damit nicht genug: Meine Generation hat es verpasst, Kinder in die Welt zu setzen, so dass die Söhne und Schwiegertöchter fehlen, die im Alter zu uns schauen können.

Das Bundesamt für Statistik rechnet damit, dass sich die Zahl der über 80-Jährigen bis 2040 verdoppeln wird. Solche Prognosen und verschiedene Vorstösse im Parlament veranlassten den Bundesrat, einen Bericht zur Zukunft der Langzeitpflege ${ }^{1}$ zu erstellen, denn der Schluss liegt nahe, dass auch die Pflegebedürftigkeit zunehmen wird. Eine Tagung des gewerkschaftsnahen Thinktanks «Denknetz» Anfang September nahm den Bundesratsbericht zum Anlass, über Modelle zur Pflege und Betreuung betagter Menschen zu diskutieren. Unter anderem stellte der Heim-Dachverband Curaviva sein «Wohn- und Pflegemodell 2030» vor, das die Zweiteilung ambulant und stationär ein Stück weit aufhebt. Das Modell baut auf dezentrale Gesundheitszentren, wo auf sich verändernde Bedürfnisse abgestimmte Dienstleistungs- und Pflegeangebote ein selbstbestimmtes Leben trotz Pflegebedürftigkeit ermöglichen. Gute Praxisbeispiele aus dem In- und Ausland wurden präsentiert. Es gibt vielversprechende Ansätze, überzeugende Ideen. Es gibt die «GrossmütterRevolution»", eine Plattform für politisch engagierte Frauen der Grossmüttergeneration. Das stimmt zuversichtlich.

Eine gute Pflege ist natürlich nicht gratis zu haben. Über die Kosten und die Finanzierung von Spitex und Pflegeheimen wird in der Schweiz auch nach der 2011 eingeführten neuen Pflegefinanzierung weiter heftig gestritten: Wie viel sollen die Pflegebedürftigen aus der eigenen Tasche bezahlen müssen, wie viel zahlt der Staat, wie viel die Krankenkasse? Braucht es eine Pflegeversicherung? Diese Fragen werden uns weiter beschäftigen, und doch sind die Kosten wahrschein- lich nicht unser grösstes Problem. In Anbetracht der absehbaren demographischen Entwicklung gibt es gute Gründe, sich zu fragen, wer in Zukunft noch bereit und in der Lage sein wird, sich um betagte und pflegebedürftige Mitmenschen zu kümmern. Es braucht auf der einen Seite professionelle Gesundheitsfachkräfte, auf der anderen Seite hilfsbereite Töchter, Schwiegersöhne, Partnerinnen, Neffen, Freundinnen und Nachbarn.

Damit sind wir wieder bei der demographischen Umschichtung angelangt. Das Schweizerische Gesundheitsobservatorium Obsan erstellte vor einigen Jahren eine eindrückliche Kurve. Diese zeigt, wie viele Frauen im Alter zwischen 35 und 60 Jahren einer über 80-jährigen Person gegenüberstehen, dies unter der Prämisse, dass Care-Arbeit vor allem Frauensache ist. Heute sind es 3,5 Töchter oder Schwiegertöchter, die als potentielle pflegende Angehörige pro betagte Person zur Verfügung stehen. 2050 werden es noch 1,4 sein. Selbst wenn die männlichen Nachkommen sich viel stärker als bisher in die Care-Arbeit einbringen, werden die Babyboomers sich nach anderen Möglichkeiten umsehen müssen, um im Alter nicht einsam und verwahrlost ihr Dasein zu fristen. Sie werden sich gegenseitig unterstützen, ihre Kräfte aufteilen und Dienstleistungen gezielt dort in Anspruch nehmen, wo sie am dringendsten benötigt werden. Sie werden Freundinnen und Freunde brauchen. Und sie werden auf solidarische Mitbürgerinnen und Mitbürger angewiesen sein, die bereit sind, die notwendigen finanziellen Mittel für professionelle Dienstleistungen im Alter bereitzustellen. Visionen wie das von Curaviva entwickelte Wohnund Pflegemodell 2030 werden hoffentlich Realität. Auch wenn ich gute Gründe hätte, mich vor dem Alter zu fürchten, tue ich es nicht. Das Leben kann noch viele Wendungen nehmen, manches kommt anders als geplant. Wir werden sehen. Ich weiss ja nicht einmal, ob ich überhaupt richtig alt werde. Aber eines weiss ich bestimmt: In einer Alters-WG werde ich nicht leben wollen, wenn es sich vermeiden lässt. Ich habe noch nie gerne in WGs gelebt. 